\title{
PETUAH TENTANG SYARIAT DALAM SYAIR SIDI DJAMADI
}

\author{
Yosi Wulandari ${ }^{1)}$, Wachid Eko Purwanto ${ }^{2)}$, Fitri Merawati ${ }^{3)}$ \\ Universitas Ahmad Dahlan \\ yosi.wulandari@pbsi.uad.ac.id,wachid.purwanto@pbsi.uad.ac.id, fitri.merawati@pbsi.uad.ac.id
}

\begin{abstract}
ABSTRAK
Penelitian ini bertujuan untuk mendeskripsikan petuah-petuah kehidupan berupa syariat dalam Syair Sidi Djamadi. Penelitian ini berjenis penelitian deskriptif kualitatif dengan metode analisis isi. Penelitian ini menggunakan konsep pemaknaan hermeneutika Paul Ricouer. Subjek penelitian ini adalah Syair Sidi Djamadi merupakan salah satu naskah nusantara dari Minangkabau dan berjumlah 761 bait. Syair tersebut dibukukan dalam bentuk jilid biasa oleh pemilik berbahasa Arab Melayu Gundul, dan terdiri atas 71 halaman. Objek penelitian ini adalah petuah-petuah kehidupan. Data dikumpulkan dengan inventarisasi data, analisis dan interpretasi, dan penyimpulan. Penelitian ini menyimpulkan bahwa sebagai salah satu naskah kuno Minangkabau Syair Sidi Djamadi memperkuat konteks kepengarangan Minang zaman dahulu yang mengutamakan nilai-nilai kehidupan yang disandingkan dengan agama. Sebagai ulama, Sidi Djamadi telah menguraikan sembilan syariat yang perlu diingat oleh masyarakat khususnya di Nagari Minangkabau. Sembilan syariat itu ialah, syariat dan adat, syariat menuntut ilmu, syariat syahadat, syariat puasa, syariat zakat, syariat salat, syariat 20 sifat wajib Allah, syariat haji, dan syariat salat tarawih.
\end{abstract}

Kata kunci: petuah, syariat, syair, Sidi Djamadi

\section{A. PENDAHULUAN}

Sebagai salah satu negara yang terkenal dengan kekayaan budaya, Indonesia merupakan negara yang memiliki naskahnaskah nusantara sebagai warisan leluhur yang menjadi perhatian dunia. Naskahnaskah nusantara tersebut saat ini menjadi pusat dan studi perhatian perpustakaan Nasional sebagai salah satu koleksi yang bernilai tinggi. Hal tersebut didasarkan pada nilai historis dan kearifan lokal yang termuat dalam naskah-naskah nusantara tersebut.

Naskah-naskah nusantara yang berasal dari berbagai penjuru ditulis dengan berbagai bahasa dan berbagai jenis aksara. Naskah Melayu merupakan bagian terbesar yang

terdapat dalam naskah nusantara. Salah satu jenis naskah Melayu yang banyak dijumpai adalah syair. Syair merupakan salah satu bentuk penyajian karya sastra yang lazim digunakan pada masa lalu. Bahkan, syair pun telah menjadi salah satu khasanah Sastra Melayu Klasik yang memuat berbagai topik, misalnya, percintaan, nasihat, tuntutan beragama, dan sebagainya.

Petuah-petuah kehidupan pun merupakan bagian dari topik syair yang lazim ditulis oleh para pujangga pada masa lalu. Petuah-petuah tersebut disajikan dengan penggunaan bahasa-bahasa yang memiliki nilai keindahan yang tinggi karena perumpaan yang digunakan disesuaikan 


\section{DEIKSIS - JURNAL PENDIDIKAN BAHASA DAN SASTRA INDONESIA}

dengan makna yang diungkapkan.

Sehubungan dengan hal tersebut, syair Sidi Djamadi merupakan salah satu naskah kuno yang berasal dari Minangkabau yang memuat petuah-petuah kehidupan bagi masyarakat. Petuah-petuah tersebut sengaja disampaikan agar manusia berada pada jalan yang lurus pada jalan yang diridai Allah dan berkahnya menyelamatkan manusia dalam kehidupan di dunia dan di akhirat. Selain itu, petuah-petuah tersebut pun perlu untuk diketahui dan dimaknai sebagai rujukan untuk menyelesaikan masalah kehidupan.

\section{A. KAJIAN TEORETIS}

Istilah petuah identik dengan nasihatnasihat yang umumnya disampaikan oleh orang tua kepada anak-anaknya. Menurut KBBI (dalam jaringan) petuah diartikan “(1) keputusan atau pendapat mufti (tentang masalah agama Islam); fatwa; (2) nasihat orang alim; pelajaran (nasihat) yang baik". Oleh karena itu, petuah merupakan bagian dari ajaran kehidupan yang umumnya selalu dijadikan pedoman dalam kehidupan.

Mardiono (2013:1) menambahkan bahwa syair sebagai bentuk puisi lama merupakan karya sastra yang amat digemari oleh orang Melayu. Bahkan, syair-syair dibaca sambil dilagukan yang dibeberapa tempat disebut bernalam atau bernazam. Dengan demikian, syair cenderung menjadi ikatan bunyi semata-mata tidak diikat oleh isi yang kuat.

Sehubungan dengan teks syair tersebut, syair merupakan salah satu jenis teks sastra yang ber-ganre puisi memiliki kekuatan pada penggunaan bahasa atau pemilihan kata dalam menyampaikan makna. Selain itu, pemaknaan puisi pun tidak dapat lepas dari pembaca. Oleh karena itu, diperlukan sebuah pendekatan atau teori digunakan sebagai acuan untuk menemukan makna pada sebuah teks sastra. Konsep pemaknaan berdasarkan teori hermeneutika Paul Ricouer menyatakan bahwa tujuan interpretasi pada konsep hermeneutika adalah untuk mengaktualisasikan makna teks kepada pembaca.

Paul Ricoeur berpandangan bahwa hermeneutika merupakan suatu teori mengenai aturan-aturan penafsiran terhadap suatu teks atau sekumpulan tanda maupun simbol yang dikelompokkannya juga sebagai teks. Salah satu tujuan hermeneutik adalah berjuang untuk melawan jarak budaya dan keterasingan sejarah. Artinya, hermeneutika berjuang menentang pemisahan dari makna itu sendiri yang menjadi landasan sebuah teks. Dengan demikian, interpretasi dipahami sebagai usaha 'menyatukan', 'menyamakan', menjadikan 'sezaman dan serupa' lalu dengan merumuskannya menjadi konsep sendiri. Interpretasi dikatakan berhasil ketika tujuan penginterptetasian tercapai, yaitu mengaktualisasikan makna teks untuk pembaca saat ini.

Selanjutnya, membaca (memaknai) syair, sama seperti halnya membaca karya sastra yang lain, perlu memperhatikan karakter dari teks syair tersebut serta memperhatikan 'langkah kerja' yang mesti dilalui. Hal tersebut dilakukan untuk mencapai tujuan utama, yaitu menemukan makna dengan empat kategori hermeneutika. Dengan demikian, kajian 


\section{DEIKSIS - JURNAL PENDIDIKAN BAHASA DAN SASTRA INDONESIA}

terhadap syair Sidi Djamadi untuk menemukan makna secara lengkap khususnya terhadap petuah-petuah kehidupan digunakan teori hermeneutika Paul Ricouer. Dengan demikian, tujuan penelitian ini adalah untuk mendeskripsikan petuah syariat dalam Syair Sidi Djamadi dengan konsep kajian hermeneutika Paul Ricouer.

\section{B. METODOLOGI}

Jenis penelitian ini adalah penelitian deskriptif kualitatif yang bersifat analisis isi. Subjek penelitian ini adalah Syair Sidi Djamadi merupakan salah satu naskah nusantara dari Minangkabau dan berjumlah 761 bait. Syair tersebut dibukukan dalam bentuk jilid biasa oleh pemilik berbahasa Arab Melayu Gundul, dan terdiri atas 71 halaman. Objek penelitian ini adalah petuah-petuah kehidupan Syair Sidi Djamadi.

Teknik pengumpulan dan analisis data dalam penelitian ini digunakan beberapa hal sebagai berikut. (1) Iventarisasi sumber data, yaitu mencatat dan mengumpulkan seluruh bahan penelitian. (2) Identifikasi data berdasarkan konsep penafsiran petuah syariat. (3) Analisis dan interpretasi, yaitu melakukan analisis dan interpretasi terhadap kaitan semua unsur yang diidentifikasi. 4) Penyimpulan, yaitu melakukan perumusan dan penyimpulan terhadap analisis dan interpretasi.

\section{PEMBAHASAN}

Petuah kehidupan berupa syariat merupakan salah satu petuah paling hakiki bagi umat beragama agar tidak salah jalan dalam mengarungi kehidupan. Sidi Djamadi menyampaikan petuah tersebut melalui syair yang diidentifikasi menjadi sembilan syariat yang disajikan dalam bentuk tabel, yaitu syariat dan adat, syariat menuntut ilmu, syariat syahadat, syariat puasa, syariat zakat, syariat salat, syariat 20 sifat wajib Allah, syariat haji, dan syariat salat tarawih.

\section{Tabel 1}

Petuah tentang Syariat dalam Syair Sidi Djamadi

\begin{tabular}{|c|c|c|}
\hline Syariat & $\begin{array}{l}\text { Nomor } \\
\text { bait }\end{array}$ & Data \\
\hline \multirow[t]{2}{*}{$\begin{array}{l}\text { Syariat } \\
\text { dan adat }\end{array}$} & 34 & $\begin{array}{l}\text { Inilah rupa desa } \\
\text { nagari / sebablah } \\
\text { runtuh syarak usoli / } \\
\text { adatlah condong kiri } \\
\text { kamari / tertampung } \\
\text { orang tiada budi }\end{array}$ \\
\hline & 35 & $\begin{array}{l}\text { Allah-allah wahai } \\
\text { sudara / kalaulah } \\
\text { tarang jalan yang lama } \\
\text { / syarak jo adat sakoto } \\
\text { jua / kota nagari } \\
\text { sanang sentosa }\end{array}$ \\
\hline $\begin{array}{l}\text { Syariat } \\
\text { menuntu } \\
\text { t ilmu }\end{array}$ & 72 & $\begin{array}{l}\text { Ahli kuna bangso } \\
\text { membitari / jangan } \\
\text { sekali berbangso diri / } \\
\text { menuntut ilmu jangan } \\
\text { berhenti / supaya } \\
\text { dapat syarak usoli }\end{array}$ \\
\hline $\begin{array}{l}\text { Syariat } \\
\text { syahadat }\end{array}$ & 89 & $\begin{array}{l}\text { Arti sahadat adakah } \\
\text { paham / hendaklah } \\
\text { ingat kepada badan / } \\
\text { jangan sahadat tiru- } \\
\text { tiruan / jauh dinabi di } \\
\text { akhir zaman }\end{array}$ \\
\hline
\end{tabular}




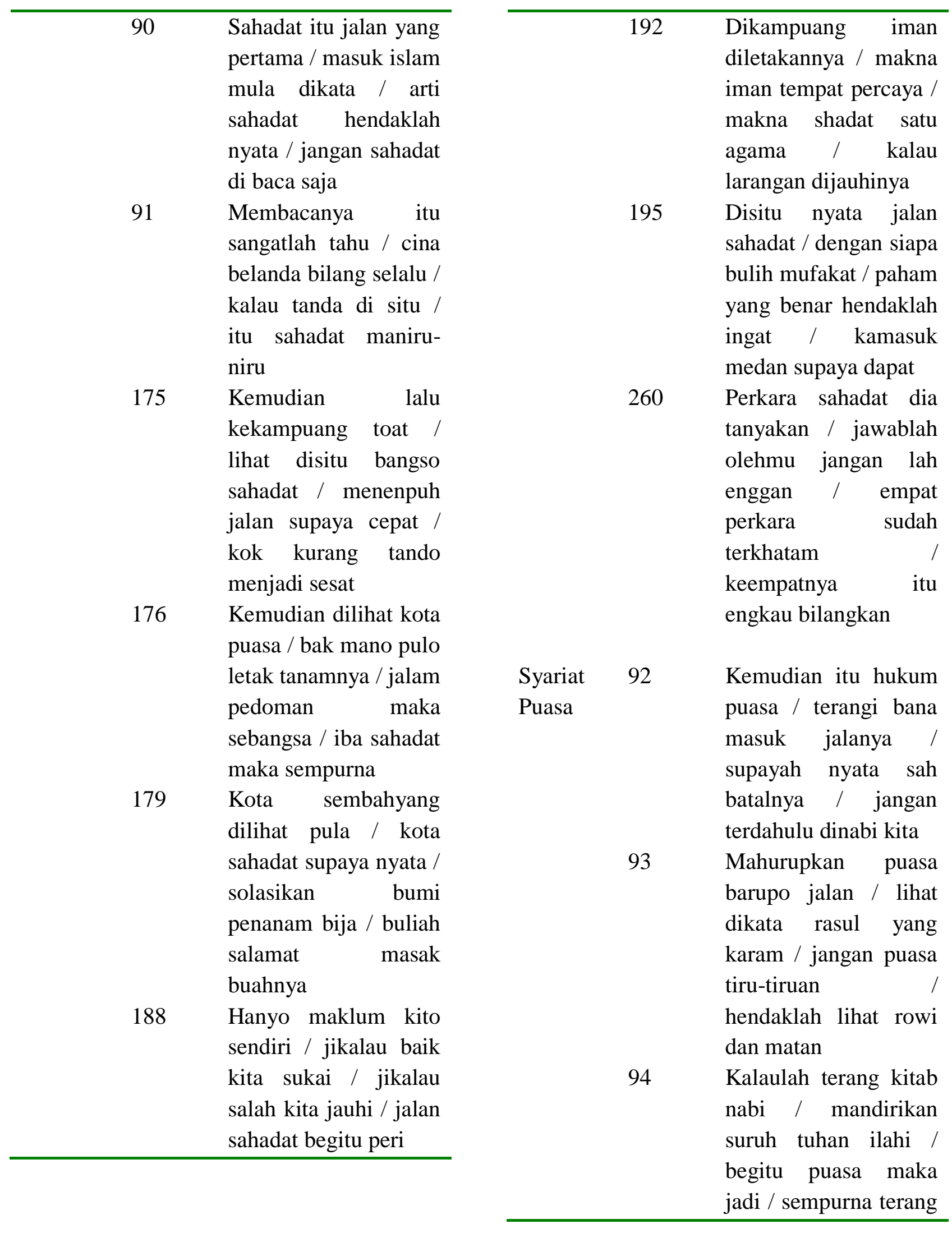




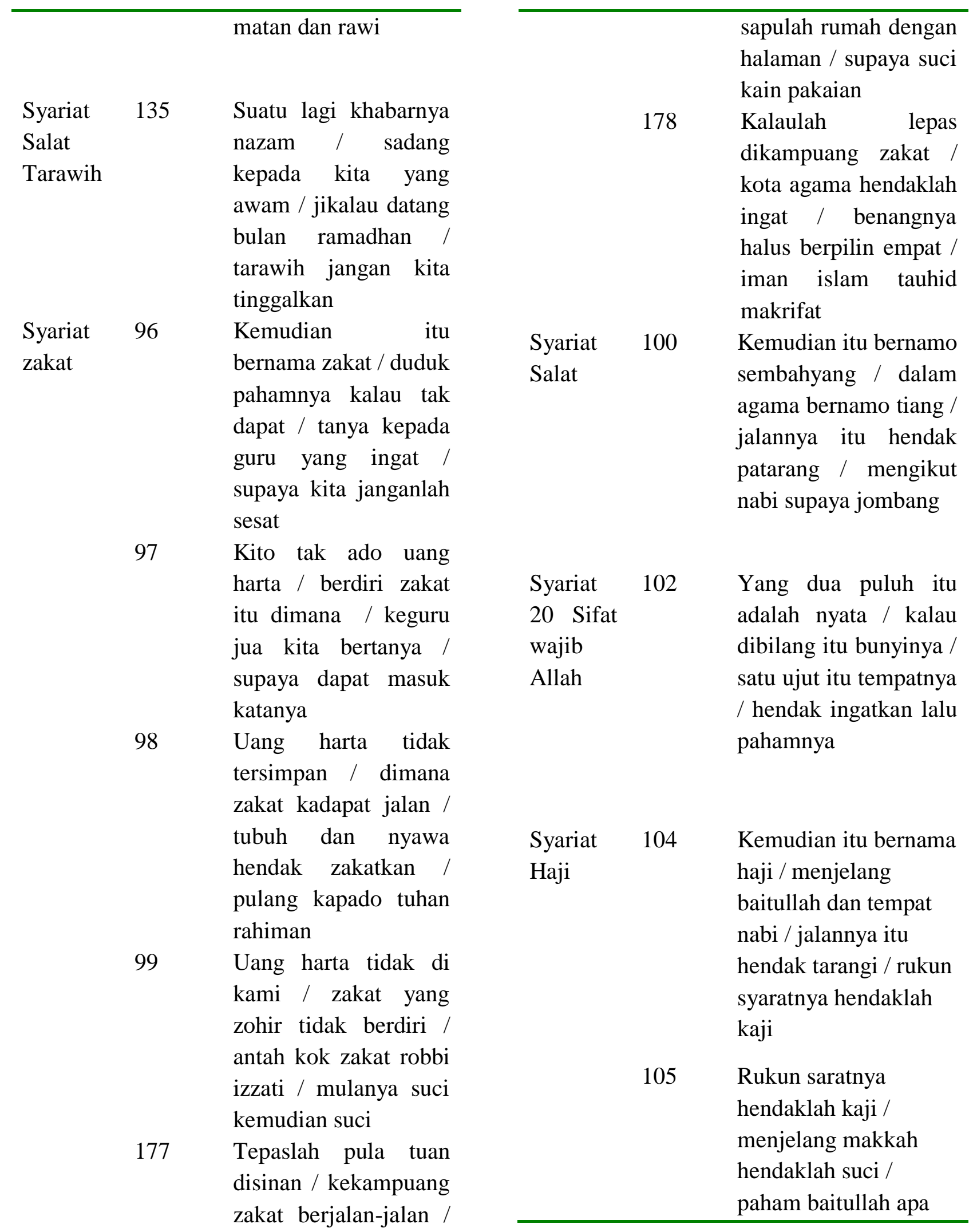




\section{DEIKSIS - JURNAL PENDIDIKAN BAHASA DAN SASTRA INDONESIA}

arti / jauh hampirnya

hendaklah cari penerapan

teori

interpretasi hermeneutik Recouer yang telah diaparkan sebelumnya, dapat dinyatakan bahwa proses interpretasi dan penafsiran pada penelitian ini mengacu pada faktor kebebasan sehingga interpretasi dan penafsiran yang dihasilkan dapat memberikan makna baru sesuai dengan kebebasan dan kreativitas peneliti.

Dengan kata lain, interpretasi dan penafsiran yang dilakukan dapat memberikan makna baru terhadap kandungan terhadap makna petuah syariat serta sesuai dengan kondisi terkini.

Syair Sidi Djamadi pada bait ke 34 dan 35 memuat syariat tentang syariat dan adat. Bait tersebut menjelaskan petuah agar masyarakat menyelaraskan hubungan syariat dan adat sehingga nagari akan damai sentosa. Selanjutnya bait ke 72 merupakan syair yang memuat syariat menuntut ilmu. Bait ke-72 tersebut menyampaikan agar terus menuntut ilmu sehingga mendapatkan pemahaman syarak yang hakiki. Sehubungan dengan syariat tersebut sesuai dengan dalil berikut.

Abud Darda' radhiyallahu 'anhu berkata: Aku mendengar Rasulullah Shallallahu 'alaihi wa sallam bersabda:

"Barangsiapa menempuh suatu jalan yang padanya dia mencari ilmu, maka Allah akan mudahkan dia menempuh jalan dari jalan-jalan (menuju) jannah, dan sesungguhnya para malaikat benar-benar akan meletakkan sayap-sayapnya untuk penuntut ilmu, dan sesungguhnya seorang penuntut ilmu akan dimintakan ampun untuknya oleh makhluk-makhluk Allah yang di langit dan yang di bumi, sampai ikan yang ada di tengah lautan pun memintakan ampun untuknya. Dan sesungguhnya keutamaan seorang yang berilmu atas seorang yang ahli ibadah adalah seperti keutamaan bulan pada malam purnama atas seluruh bintang, dan sesungguhnya ulama adalah pewaris para Nabi, dan para Nabi tidaklah mewariskan dinar ataupun dirham, akan tetapi mereka hanyalah mewariskan ilmu, maka barangsiapa yang mengambilnya maka sungguh dia telah mengambil bagian yang sangat banyak." (HR. Abu Dawud no.3641, At-Tirmidziy no.2683, dan isnadnya hasan, lihat Jaami'ul Ushuul 8/6)

Dengan demikian, syariat menuntun ilmu yang disampaikan Sidi Djamadi tersebut sesuai dengan nasihat-nasihat yang disampaikan oleh Nabi Muhammad Saw.

Selanjutnya, syariat syahadat disampaikan pada bait 89-91, 175, 176, 179, 188, 192, 260. Sembilan bait tersebut menyampaikan petuah syariat syahadat yang dimulai dari pemaknaan terhadap syahadat dan penerapan syahadat dalam kehidupan sehari-hari. Sehubungan dengan syahadat tersebut, bait ke-89 didukung oleh hadis nabi dari Ubadah bin al-Shamit, aku mendengar Rasulullah SAW bersabda, 'Barang siapa yang bersaksi tiada tuhan selain Allah dan bahwasanya Muhammad adalah utusan Allah, maka Allah akan mengharamkam neraka baginya". (HR. 


\section{DEIKSIS - JURNAL PENDIDIKAN BAHASA DAN SASTRA INDONESIA}

Muslim). Bait ke-90 sesuai dengan dalil Allah berikut.

Dan, ketika Tuhanmu mengeluarkan keturunan anak-anak Adam dari sulbi mereka dan Allah mengambil kesaksian terhadap jiwa mereka, "Bukankah Aku ini Tuhanmu?" Mereka menjawab, "Betul, kami menjadi saksi." agar di hari kiamat kamu tidak mengatakan, "Sesungguhnya kami adalah orang-orang yang lengah terhadap ini. " (QS Al-A'raf: 172 )

Berdasarkan surat Al-A'raf dan sabda nabi tersebut dapat dinyatakan bahwa syahadat merupakan bagian terpenting ketauhidan umat Islam yang bersaksi dan mengimani arti syahadatnya.

Kemudian, syariat puasa dipaparkan pada bait 92, 93, dan 94. Pada bait-bait tersebut disampaikan sehubungan dengan hukum puasa dan hal-hal yang berkaitan dengan puasa. Bait ke-92 sesuai dengan firman Allah berikut.

Allah berfirman, "Semua amal anak Adam baginya, kecuali puasa. Sesungguhnya puasa itu untuk-Ku dan Aku sendiri yang akan membalasnya. Puasa adalah perisai. Apabila salah seorang kalian sedang menjalani puasa janganlah dia berkata-kata kotor dan berteriak-teriak. Apabila ada orang yang mencaci atau memeranginya hendaklah dia katakan, 'Sesungguhnya saya sedang berpuasa.' Demi Tuhan yang jiwa Muhammad berada di tangan-Nya, bau mulut orang yang berpuasa jauh lebih harum daripada bau minyak kasturi. Orang yang berpuasa memiliki dua kebahagiaan. Ketika dia berhariraya dan ketika dia berjumpa dengan Rabbnya maka dia akan bergembira dengan puasanya." (HR. Bukhari dalam Kitab asShiyam) berikut.

Bait ke-93 diperkuat pula pada dalil

Puasa adalah perisai. Maka janganlah dia berkata-kata kotor dan berbudat bodoh. Apabila ada orang lain yang memerangi atau mencacinya, hendaklah dia katakan, 'Aku sedang puasa' (dua kali). Demi Tuhan yang jiwaku berada di tangan-Nya, sesungguhnya bau mulut orang yang berpuasa itu lebih harum di sisi Allah ta'ala daripada bau minyak kasturi. Dia rela meninggalkan makanan, minuman, dan syahwatnya karena Aku. Puasa itu untuk-Ku dan Aku sendiri yang akan membalasnya. Satu kebaikan dibalas sepuluh kali lipatnya." (HR. Bukhari dalam Kitab asShiyam).

Setelah itu, syariat lain yang disampaikan adalah syariat salat tarawih, yaitu pada bait 135. Bait tersebut memberikan petuah agar tidak meninggalkan salat tarawih pada bulan puasa. Hal ini sesuai hadis nabi berikut.

Aisyah Radhiyallahu anhuma ditanya: "Bagaimana shalat Rasul Shallallahu 'alaihi wa sallam pada bulan Ramadhan?" Dia menjawab, "Beliau tidak pemah menambah -di Ramadhan atau di luarnya- lebih dari 11 raka'at. Beliau shalat empat rakaat, maka jangan ditanya tentang bagusnya dan lamanya. Kemudian beliau shalat 3 raka'at." [HR Bukhari]

Syariat selanjutnya adalah syariat zakat yang disampaikan pada enam bait, yaitu 96-99, 177, dan 178. Keenam bait tersebut menyampaikan petuah-petuah agar manusia tidak lupa berzakat dan 


\section{DEIKSIS - JURNAL PENDIDIKAN BAHASA DAN SASTRA INDONESIA}

kepentingan zakat sehubungan dengan rezeki yang telah dimiliki. Sehubungan dengan petuah tersebut, petuah itu pun dijelaskan dalam Alquran sebagai berikut.

Dan orang-orang yang menyimpan emas dan perak dan tidak menafkahkannya pada jalan Allâh, maka beritahukanlah kepada mereka (bahwa mereka akan mendapat) siksa yang pedih. Pada hari dipanaskan emas dan perak itu dalam neraka Jahannam, lalu dahi, lambung dan punggung mereka dibakar dengannya, (lalu dikatakan) kepada mereka: "Inilah harta bendamu yang kamu simpan untuk dirimu sendiri, maka rasakanlah sekarang (akibat dari) apa yang kamu simpan itu”. (QS. at-Taubah/9:34-35)

Ambillah zakat dari sebagian harta mereka, dengan zakat itu kamu membersihkan dan mensucikan mereka dan mendoalah untuk mereka(QS. At-Taubah :103)

Kemudian, syariat salat disampaikan pula pada bait ke-100 yang menyampaikan ajaran untuk salat dan tidak meninggalkan salat karena salat adalah tiang agama dan memberikan kebaikan untuk kehidupan manusia. Hal tersebut juga sesuai dengan hadis berikut.

Shalat adalah tiang agama. Barang siapa yang menegakkan shalat,maka berarti ia menegakkan agama, dan barang siapa yang meninggalkan shalat berarti ia merobohkan agama”. (HR. Bukhari Muslim)

Syariat selanjutnya, syariat memahami dua puluh sifat wajib Allah terdapat pada bait 102. Bait tersebut menyampaikan secara implisit, yaitu Yang dua puluh itu adalah nyata / kalau dibilang itu bunyinya / satu ujut itu tempatnya / hendak ingatkan lalu pahamnya/. Bait tersebut menguraikan bahwa perlu diketahui dan dipahami sifat wajib Allah tersebut.

Syariat yang selanjutnya ialah syariat haji, syariat ini terdiri atas dua bait yang mengungkapkan tentang perlunya memahami dan memenuhi rukun-rukun haji. Salah satu rukun wajib haji adalah niat, hal ini sesuai dengan dalil sebagai berikut.

"Padahal mereka tidak disuruh kecuali supaya menyembah Allah dengan memurnikan ketaatan kepada-Nya dalam (menjalankan) agama yang lurus..." [AlBayyinah: 5]

Secara umum, penemuan terhadap petuah syariat tersebut merupakan bentuk dokumentasi hasil pemikiran Ulama Minangkabau yang dahulu saat polemik keislaman terjadi banyak para ulama yang menuliskan pemikirannya dan saat ini naskah-naskah itulah yang menjadi dokumentasi sejarah. Sidi Djamadi pun dianggap merupakan salah satu ulama yang menuliskan pemikiran keaagamaan sehingga petuahnya tersebut dapat menjadi pedoman bagi masyarakat untuk belajar agama yang baik.

Sehubungan dengan hal tersebut, Pramono dan Zalik (2013) menambahkan penjelasan dari hasil kajiannya bahwa pada konteks pedebatan dan polemik keislaman di Minangkabau ditemukan para ulama yang mengajar di suatu surau, menyalin dan menulis naskah. Naskah-naskah yang disalin dan ditulis tersebut ditujukan untuk menyebarkan pengajian dan mendebat ataupun mengkritik pendapat orang lain serta keadaan sosial. Hal ini 
menggambarkan bahwa surau bukan sekedar tempat belajar membaca Alquran atau belajar adab, melainkan surau merupakan pusat kecendekiaan, center for excelent. Hal ini sekaligus kesan bahwa yang dilakukan para ulama tarekat, dalam mempertahankan paham keagamaannya, adalah bagian dari kebiasaan berdebat yang dikembangkan di kalangan ulama, sebuah kegiatan intelektual Islam di Minangkabau.

\section{SIMPULAN}

\section{a. simpulan}

Berdasarkan hasil dan pembahasan dapat disimpulkan hal berikut. Petuah syariat yang terdapat dalam syair Sidi Djamadi ada sembilan syariat, yaitu syariat dan adat, syariat menuntut ilmu, syariat syahadat, syariat puasa, syariat salat tarawih syariat zakat, syariat salat, syariat 20 sifat wajib Allah, dan syariat haji. Syariat-syariat tersebut berisi petuah-petuah bagi masyarakat untuk menjalankan kehidupan beragama. Syariat tersebut merupakan hasil catatan ulama Minangkabau untuk pedoman hidup beragama masyakat. Selain itu, Syair Sidi Djamadi memperkuat konteks kepengarangan Minang zaman dahulu yang mengutamakan nilai-nilai kehidupan yang disandingkan dengan agama.

\section{b. Saran}

Sehubungan dengan hasil penelitian, dapat disarankan bahwa diperlukan pengkajian lebih lanjut sehubungan dengan naskah kuno lainnya untuk mendapatkan petuah atau ajaran-ajaran kehidupan yang dapat dijadikan pedoman dalam kehidupan bermasyarakat.

\section{E. DAFTAR PUSTAKA}

Mardiono. 2013. Antologi Syair Keagamaan dalam Sastra Melayu Klasik. Jakarta: Perpustakaan Nasional RI.

Pramono dan Zahir Ahmad. (2013). "Beberapa Catatan terhadap KitabKitab Karya Ulama Minangkabau pada Permulaan Abad XX". Wacan Etnik, Jurnal Sosial dan Humaniora, Volume 4, Nomor 2, halaman 111122. 